\title{
Retenção de aroma na secagem em atmosferas normal e modificada: desenvolvimento do sistema de estudo
}

\author{
Aroma retention in drying with normal and modified atmosphere: development of a study system
}

\author{
Marcilio Machado MORAIS ${ }^{1 \star}$, Maria Aparecida SILVA²
}

\begin{abstract}
Resumo
Na secagem de determinados alimentos, como frutas, juntamente com a água há também a evaporação de outras substâncias voláteis presentes em quantidades menores. Por isso, torna-se interessante considerar nos estudos de secagem a evaporação, além da água, desses outros componentes voláteis. A modificação da atmosfera tem sido utilizada em armazenamento, principalmente de vegetais, mas pode também ser estendida à secagem, pois pode influenciar a perda de voláteis responsáveis pelas características sensoriais do produto final. No presente trabalho, é apresentado um sistema de secagem previamente desenvolvido, no qual a atmosfera de secagem pode ser modificada pela adição de gases ou líquidos. Desenvolveu-se um sistema-modelo a partir da composição química básica do abacaxi e da adição de outros compostos, contendo um dos principais componentes do aroma desta fruta (hexanoato de etila). Além disso, também foi desenvolvida a metodologia analítica de determinação do aroma no sistema-modelo e no abacaxi, a partir dos estudos de extração de aromas e de análise cromatográfica gasosa. $\mathrm{O}$ aroma presente no sistema-modelo foi extraído em hexano e os componentes voláteis do aroma do abacaxi foram extraídos em éter etílico.
\end{abstract}

Palavras-chave: túnel de secagem; ágar-ágar; extração de voláteis; cromatógrafo gasoso; análise do headspace; polímero Porapak Q.

\begin{abstract}
In the drying of some foods such as fruits, besides water there is also the evaporation of other volatile substances present in lesser amounts. Therefore, it is interesting to consider the evaporation of volatile components other than water in drying studies. The modification of atmosphere has been used for storage only, especially for vegetables, but it can be extended to drying since it can influence the loss of volatile components responsible for the sensorial characteristics of the final product. In the present study, a drying system previously developed, in which the drying atmosphere can be modified by the addition of gases or liquids, was presented. A model-system was developed from the basic chemical composition of pineapple and the addition of other compounds containing one of the main aroma components (ethyl hexanoate). An analytical methodology for determing the aroma components present in the model-system and in the pineapple was developed from the studies of aroma extraction and gas chromatography. The aroma present in the model-system was extracted with hexane, and the volatile aroma components of the pineapple were extracted with ethylic ether.

Keywords: drying tunnel; agar-agar; extraction of volatiles; gaseous chromatograph; headspace analysis; Porapak Q polymer.
\end{abstract}

\section{Introdução}

O processo usual de secagem de determinados alimentos, como frutas, pode promover uma perda de substâncias voláteis presentes em quantidades menores, juntamente com a água. Quando tais substâncias possuem características odoríferas, o produto final seco pode perder qualidade com relação ao seu aroma.

Dentre as frutas tropicais, o abacaxi é uma das mais consumidas, tanto in natura como industrializado, sendo o Brasil um dos grandes produtores mundiais da fruta. O aroma característico do abacaxi é de grande aceitação pelo consumidor, mas tende a ser perdido significativamente durante o processo de secagem convencional. Dessa forma, a remoção preferencial de água e a retenção dos outros componentes, tais como os componentes voláteis relacionados ao aroma, tornam-se objetivos muito importantes durante a secagem (LUNA; MARTÍNEZ, 1997).

A modificação de atmosfera, com controle ou não, é muito utilizada no armazenamento de vegetais, aumentando a vida útil dos produtos armazenados e conservando mais o aroma, a cor e o frescor dos alimentos. A modificação da atmosfera também pode ser aplicada ao processo de secagem por meio da incorporação de aditivos voláteis ao gás de secagem. Assim, pode-se inferir que o uso da atmosfera modificada em processos de secagem pode diminuir ou evitar a perda de voláteis responsáveis pelas características sensoriais do produto, por meio da alteração das volatilidades relativas desses componentes. No entanto, pouco se conhece sobre a influência da composição da atmosfera de secagem no comportamento da evaporação dos referidos voláteis durante a secagem, havendo

Received 14/8/2008

Accepted 14/2/2010 (003712)

${ }^{1}$ Universidade Federal do Pampa - UNIPAMPA, Campus Bagé, Travessa 45, 1650, CEP 96413-170, Bairro Malafaia, Bagé, RS, Brasil,

E-mail: marciliomorais@unipampa.edu.br

${ }^{2}$ Faculdade de Engenharia Química, Universidade Estadual de Campinas - UNICAMP, Av. Albert Einstein, 500, CEP 13083-852, Campinas, SP, Brasil,

E-mail: cida@feq.unicamp.br

${ }^{*}$ Corresponding author 
poucos trabalhos na literatura sobre o assunto em questão (SCHULTZ; SCHLÜNDER, 1990; PANG, 2006; TIETZ; SCHLÜNDER, 1993; O'NEILL et al., 1998; RAMESH et al., 1999; KUDRA; POIRIER, 2005; HAWLADER et al., 2006). Apenas o trabalho realizado por Hawlader, Perera e Tian (2006) trata da retenção de componentes voláteis, isto é, retenção de 6-gingerol na secagem de gengibre em atmosfera modificada com nitrogênio e com gás carbônico. Na literatura, há uma carência de trabalhos que utilizem equipamentos que permitam a modificação e o controle da composição do agente secante durante o processo de secagem. Como é interessante verificar a influência da composição do gás de secagem nas características do produto final seco, justifica-se a necessidade do desenvolvimento de secadores compatíveis com tal fim.

Em sistemas reais, como é o caso do abacaxi, a composição química das amostras in natura provenientes de diferentes frutas é variável, assim como a sua matriz sólida possui um arranjo de grande complexidade. Dessa forma, o desenvolvimento de um sistema-modelo de estrutura mais simplificada, cuja composição inicial e concentração de aroma (um único componente) pudessem ser sempre repetidas, permitiria um melhor entendimento do fenômeno de retenção/remoção de voláteis.

Para se estudar a retenção/remoção de aroma durante a secagem, há a necessidade de isolar e quantificar as substâncias aromáticas. No entanto, essas etapas são críticas, pois os voláteis presentes em alimentos, especialmente nas frutas, são um grupo altamente diversificado, existindo em concentrações extremamente baixas (BELITZ; GROSH, 1988); além disso, esses constituintes normalmente são termolábeis (GARRUTI, 2001). Em função dessas características, podem-se analisar os componentes que se encontram na forma de vapor sobre o alimento e que alcançam a mucosa olfativa (BELITZ; GROSH, 1988). Umas das técnicas de análise é a chamada "análise dinâmica do headspace", segundo a qual os compostos voláteis são arrastados até um pequeno tubo de vidro empacotado com um leito de adsorvente, no qual são coletados. $\mathrm{O}$ arraste pode ser utilizado por um fluxo de nitrogênio purificado (BADINGS et al., 1984 apud GARRUTI, 2001) ou por meio de sucção (vácuo) (FRANCO; RODRIGUEZ-AMAYA, 1983).

Segundo as considerações feitas na presente introdução, é apresentado o sistema de secagem construído para operar em atmosferas normal e modificada. Com a finalidade de se verificar a influência da composição do agente secante na retenção de aroma, foi desenvolvido um sistema-modelo substitutivo do abacaxi, constituído por uma matriz sólida obtida a partir da composição química básica da referida fruta e por um dos principais componentes do aroma do abacaxi. Além disso, foi desenvolvida a metodologia analítica para a extração e a quantificação do aroma presente no sistema-modelo e no abacaxi in natura e seco.

\section{Material e métodos}

\subsection{Sistema de secagem com atmosfera modificada e controlada}

O equipamento construído para se realizarem os experimentos de secagem foi baseado em um túnel de secagem em atmosfera normal desenvolvido por Kairui e Pakowski (1996). Os detalhes construtivos do equipamento e de seus acessórios podem ser encontrados em Morais e Silva (2004). Na Figura 1, é apresentado um esquema do equipamento, e na Figura 2, pode ser observada uma fotografia do sistema para secagem em atmosferas modificada e controlada.

O sistema de secagem é composto de um túnel feito de policarbonato, pelo qual o gás pode ser recirculado ou descartado. A amostra é colocada no secador e o experimento de secagem pode ser iniciado nas condições desejadas (umidade relativa, temperatura, velocidade e composição do ar). O processo é monitorado continuamente pelo computador, registrando tempo, massa da amostra e temperatura do gás. A sua composição pode ser modificada e controlada pela adição de outros fluidos, como gases - nitrogênio, por exemplo - ou líquidos, como o etanol. Se forem adicionados gases para modificar a atmosfera de secagem, estes podem estar presentes desde baixas concentrações até 100\%; no caso dos líquidos, podem ser adicionados desde concentrações muito baixas até um limite de concentração em que ocorra a sua total evaporação na corrente gasosa.

\subsection{Desenvolvimento de um sistema-modelo substitutivo do abacaxi}

O sistema-modelo foi desenvolvido a partir da composição química básica do abacaxi (Tabela 1) e da adição de um componente padrão de seu aroma.

Conforme pode ser observado na Tabela 1, o abacaxi é formado basicamente por água, açúcares (mono e dissacarídios) e material fibroso. Por isso, além dos componentes mostrados na Tabela 1, foi também necessária a adição de agentes geleificantes que fornecessem uma estrutura firme à matriz sólida do sistema-modelo; os agentes geleificantes testados para tal fim foram: gelatina, pectina, amido e ágar. A descrição detalhada dos referidos testes encontra-se em Morais, Santos e Silva (2004).

Com relação à fonte dos insumos utilizados, o ágar (ágar-ágar, Gelidium cartilagineum) foi proveniente da empresa Onda Científica Ltda; a celulose microcristalina (diâmetro de partícula menor do que $160 \mu \mathrm{m}$ ), da Microcel, e os açúcares - sacarose $(P A-A C S)$, glicose $(D$-glicose anidra $P A-A C S)$ e frutose (USP/FCC) -, da marca Synth.

O padrão de aroma utilizado foi o hexanoato de etila (Sigma-Aldrich, grau de pureza $\geq 99 \%$ ), por ser um dos componentes de grande impacto no aroma do abacaxi (TAKEOKA et al., 1989).

O sistema experimental utilizado para o desenvolvimento do sistema-modelo é formado por um sistema fechado composto por um Erlenmeyer de vidro e um termômetro, no qual os insumos, constituintes do sistema-modelo, foram misturados e aquecidos. A agitação e o aquecimento foram realizados por dois agitadores magnéticos com aquecimento: o primeiro (marca Onda Científica Ltda, mod. ON-105) com 600 W de potência e

Tabela 1. Composição química básica da polpa de abacaxi maduro.

\begin{tabular}{lr}
\hline Água (\%) & 85,0 \\
Fibras (celulose) (\%) & 0,5 \\
Sacarose (\%) & 9,4 \\
Glicose e Frutose (\%) & 5,1 \\
\hline
\end{tabular}

Fonte: Medina et al. (1987). 


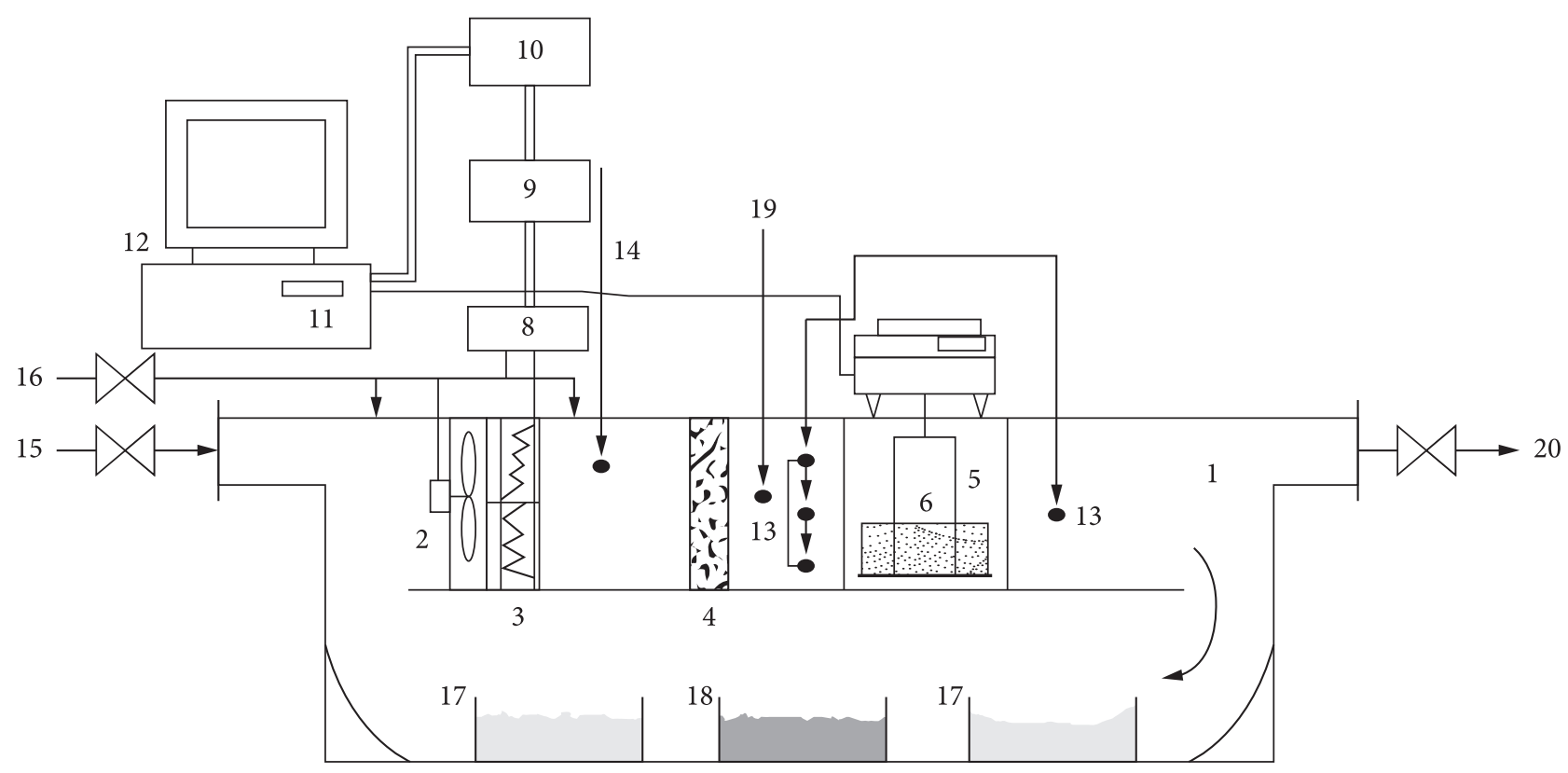

1 - Túnel de policarbonato

2 - Ventilador

3 - Sistema de aquecimento

4 - Equalizadores do fluxo de gás

5 - Porta-amostra

6 - Amostra

7 - Balança eletrônica
8 - Relês de estado sólido

9 - Controlador Lógico Programável (CLP)

10 - Fotoacopladores

11 - Sistema de aquisição de dados

12 - Microcomputador

13 - Termopares

14 - Entrada de líquido
15 - Entrada do ar

16 - Entrada de outro gás

17 - Bandejas com soluções salinas

18 - Bandeja com sílica

19 - Pontos de medida da velocidade e da umidade relativa do gás de secagem 20 - Saída do gás

Figura 1. Esquema do sistema utilizado no processo de secagem.

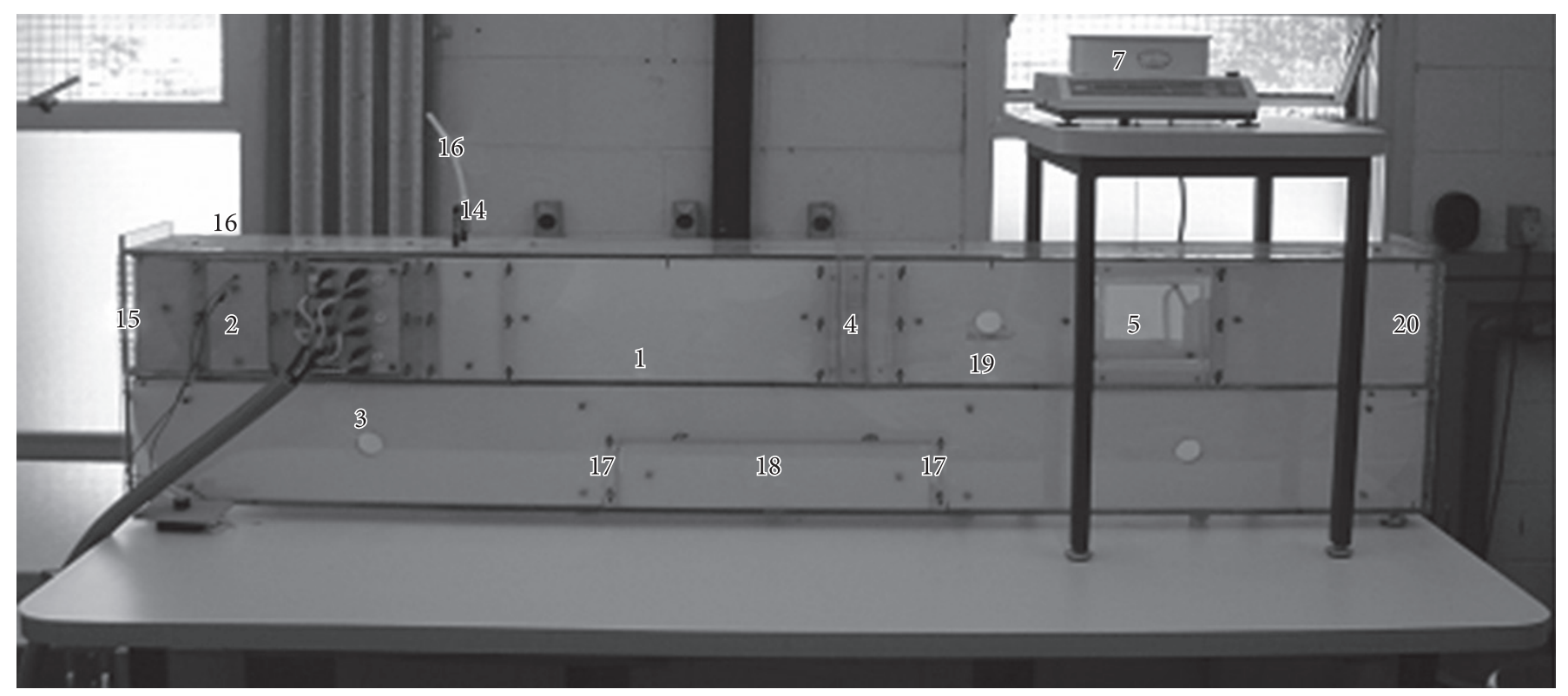

Figura 2. Equipamento utilizado nos experimentos de secagem sob atmosferas normal e modificada (mesma numeração utilizada na Figura 1).

o segundo (marca Fisatom, mod. 753A) com 900 W de potência. A velocidade máxima de agitação do primeiro agitador foi correspondente a $20 \%$ de sua capacidade máxima de agitação e o calor fornecido foi equivalente a $80 \%$ da sua capacidade máxima de aquecimento. A velocidade de agitação do segundo agitador magnético foi de aproximadamente $500 \mathrm{rpm}$ e o calor fornecido correspondeu à escala do equipamento de $250^{\circ} \mathrm{C}$.

\subsection{Extração e determinação do componente de aroma do sistema-modelo}

A metodologia de extração de aroma foi desenvolvida a partir do modelo proposto por Liu et al. (2000) para a extração de voláteis. Inicialmente, a amostra foi fundida integralmente para que o composto de aroma presente no sistema-modelo 
fosse extraído em um solvente orgânico (hexano) e a sua concentração determinada por cromatografia gasosa.

Os testes de extração do aroma foram realizados em um banho finito (marca Lab-Line ${ }^{\circledast}$, mod. 3540, de $1150 \mathrm{~W}$ de potência); as condições de operação do equipamento para a agitação foram de 40 a $400 \mathrm{rpm}$ e, para o aquecimento, de 0 a $65^{\circ} \mathrm{C}\left( \pm 0,5^{\circ} \mathrm{C}\right)$. O solvente utilizado para a extração do aroma foi o hexano (grau cromatográfico, da marca Mallinckrodt).

A cromatografia gasosa foi realizada em um Cromatógrafo Gasoso marca Varian Star 3600 CX, com coluna cromatográfica tipo $D B-1$ de $0,25 \mathrm{~mm}$ de diâmetro interno e $30 \mathrm{~m}$ de comprimento. $\mathrm{O}$ tamanho dos picos neste cromatógrafo foi quantificado por unidades de área ("counts" - unidade de medida própria do equipamento) dos referidos picos.

\subsection{Extração e determinação dos voláteis do abacaxi}

Os compostos voláteis de abacaxi (variedade Smooth Cayenne) in natura e desidratado no sistema de secagem (Figura 2) foram isolados por meio da técnica de análise dinâmica do headspace, sendo capturados em uma armadilha de Porapak Q, por sucção. O sistema de extração (Figura 4) foi montado a partir do esquema mostrado na Figura 3.

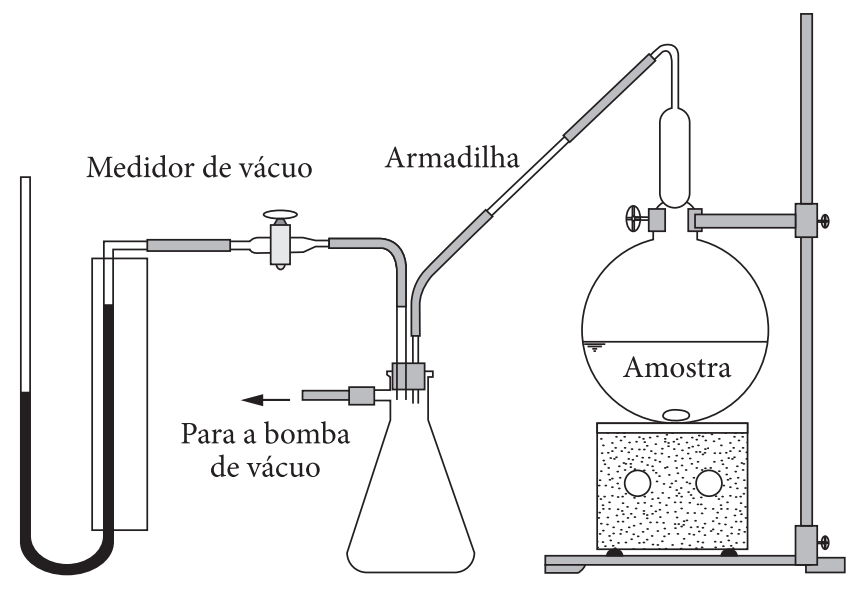

Figura 3. Esquema do sistema de coleta dos voláteis de abacaxi por amostragem dinâmica do headspace.

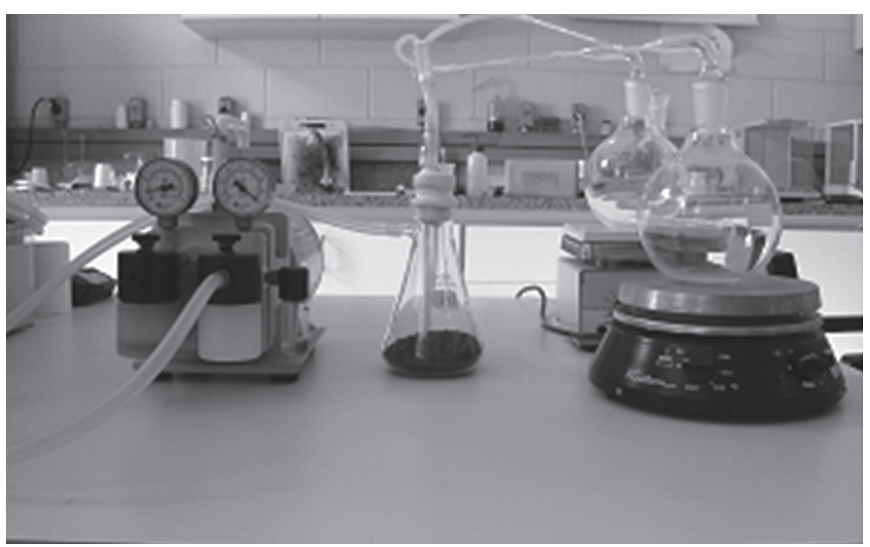

Figura 4. Sistema de extração e coleta dos voláteis de abacaxi montado no Laboratório.
O sistema de extração apresentado na Figura 4 é constituído basicamente de dois balões de vidro de fundo chato $(1000 \mathrm{~mL})$ conectados, cada um, a uma armadilha de Porapak Q, os quais, por sua vez, foram conectados a um Kitassato (contendo sílica gel) e, este último, a uma bomba de vácuo (potência de 0,25 CV da marca Quimis ${ }^{\circledast}$ mod. Q335B). Deste modo, os compostos voláteis de duas amostras podem ser extraídos simultaneamente. As amostras foram submetidas à agitação na temperatura ambiente (aproximadamente $25^{\circ} \mathrm{C}$ ), usando-se dois agitadores magnéticos nos experimentos: o primeiro (marca Onda Científica Ltda, mod. ON-105) com 600 W de potência e o segundo (marca Fisatom, mod. 753A) com 900 W de potência. A velocidade de agitação do primeiro correspondeu a 30\% de sua capacidade máxima de agitação e a do segundo, correspondeu a aproximadamente $770 \mathrm{rpm}$.

\section{Sistema de captura de voláteis}

O sistema de captura foi montado a partir de um tubo de vidro Pirex de $4 \mathrm{~mm}$ de diâmetro interno, 0,9 $\mathrm{mm}$ de espessura e $14 \mathrm{~cm}$ de comprimento, empacotando-se $60 \mathrm{mg}$ do polímero Porapak Q (80-100 mesh) (Alltech Associates Inc.) entre mechas de lã de vidro silanizadas. Após o empacotamento, as armadilhas foram condicionadas, sendo submetidas a uma temperatura de aproximadamente $170{ }^{\circ} \mathrm{C}$ em uma estufa com circulação forçada de ar (marca Quimis', mod. Q314M), com escoamento de cerca de 30-40 mL/minuto de nitrogênio (cód. N-50 da Air Liquide) ultrapuro (com 99,999\% de pureza) no interior dos tubos empacotados durante 36 horas. O condicionamento das armadilhas foi necessário a fim de que se eliminassem possíveis contaminantes e interferentes na análise do aroma do abacaxi. Após cada extração, as armadilhas foram regeneradas, injetando-se cerca de $1 \mathrm{~mL}$ de hexano no sistema de captura por quatro vezes, para garantir a remoção completa dos compostos adsorvidos no polímero poroso; logo a seguir, as armadilhas foram condicionadas no sistema descrito por um tempo de 16 horas.

\section{Condições do processo de extração}

As amostras de abacaxi (cerca de $10 \mathrm{~g}$ ) in natura ou desidratadas foram homogeneizadas com cerca de $100 \mathrm{~mL}$ de solução saturada de $\mathrm{NaCl}$ - para prevenir e inibir a ocorrência de transformações enzimáticas nas amostras durante a homogeneização, conforme foi sugerido por Maarse (1991) e $20 \mathrm{~mL}$ de água destilada em um processador (marca Walita, mod. Beta de $270 \mathrm{~W}$ de potência), sendo imediatamente colocadas no sistema apresentado na Figura 4. A extração dos voláteis foi realizada à temperatura ambiente (ao redor de $\left.27^{\circ} \mathrm{C}\right)$, sob vácuo de 12,57 - 12,96 psi $\left(86,62-89,31 \mathrm{kN} . \mathrm{m}^{-2}\right)$. Após a captura dos voláteis pelo Porapak $Q$, estes foram eluídos injetando-se $300 \mu \mathrm{L}$ de solvente na armadilha com o auxílio de uma seringa de vidro de $5 \mathrm{~mL}$; a seguir, foram injetados cerca de $5 \mathrm{~mL}$ de ar ambiente na armadilha para pressionar a saída de solvente do polímero, completando assim a etapa de eluição. A solução resultante (solvente + voláteis) foi simultaneamente recolhida em um Vial de 1,8 $\mathrm{mL}$, previamente resfriado a aproximadamente $0{ }^{\circ} \mathrm{C}$, e colocada em um freezer a $-15^{\circ} \mathrm{C}$ para posterior análise cromatográfica. 
O tempo de coleta dos compostos voláteis assim como o tipo de solvente foram parâmetros determinados neste estudo. Assim, os tempos de extração escolhidos para os testes no presente trabalho foram de 3 horas e 4,5 horas. Os solventes usados na eluição dos compostos voláteis foram o hexano (grau cromatográfico da marca Mallinckrodt) e o éter etílico (grau cromatográfico da marca Mallinckrodt).

\section{Determinação dos compostos voláteis do aroma do abacaxi}

Os isolados obtidos a partir da extração dos voláteis do abacaxi foram analisados em um cromatógrafo gasoso da marca CHROMPACK (modelo CP 9001), com uma coluna cromatográfica apresentando as seguintes características: tipo WCOT Fused Sílica; fase estacionária: CPSIL - 5CB; comprimento: $60 \mathrm{~m}$; diâmetro interno: $0,25 \mathrm{~mm}$; diâmetro externo: $0,39 \mathrm{~mm}$. As condições cromatográficas foram: temperatura inicial da coluna: $40{ }^{\circ} \mathrm{C}$; temperatura final da coluna: $230{ }^{\circ} \mathrm{C}$; rampa: $5{ }^{\circ} \mathrm{C} /$ minuto; temperatura do injetor: $220{ }^{\circ} \mathrm{C}$; temperatura do detector: $250{ }^{\circ} \mathrm{C}$; pressão na coluna: $140 \mathrm{kPa}$. A quantidade de amostra injetada no cromatógrafo foi de $3 \mu \mathrm{L}$.

A quantificação dos componentes de aroma das amostras de abacaxi in natura provenientes da mesma fruta foi realizada pela comparação da área dos principais picos fornecidos pelos cromatogramas. Quando os resultados a serem analisados eram de amostras com umidades diferentes (fruta in natura ou submetida ao processo de secagem), a quantificação do aroma do headspace foi realizada a partir da área dos principais picos fornecidos pelos cromatogramas por massa de sólido seco. No cromatógrafo usado nestas análises, a área dos picos é quantificada pela unidade $\mu \mathrm{V}^{\star}$ s.

\section{Resultados e discussão}

\subsection{Sistema-modelo substitutivo do abacaxi}

Quando o ágar foi utilizado como agente geleificante na preparação do sistema-modelo, todos os componentes (água, celulose microcristalina, sacarose, glicose, frutose e ágar) foram misturados (massa inicial total de $100 \mathrm{~g}$ ) no sistema fechado e aquecidos até a temperatura de aproximadamente $97^{\circ} \mathrm{C}$, sob agitação de semivigorosa a vigorosa (200 a $500 \mathrm{rpm}$ ), por um tempo de 10 minutos. Atingida a temperatura, a amostra foi resfriada lentamente à temperatura ambiente, com agitação eventual para uniformizar a temperatura da mistura. Quando a temperatura atingiu $50{ }^{\circ} \mathrm{C}$, adicionoaram-se $15 \mathrm{~mL}$ (cerca de $14,8 \mathrm{~g}$ ) de uma solução aquosa contendo o composto de aroma (concentração ao redor de $1000 \mathrm{mg}$ aroma. $\mathrm{kg}^{-1}$ solução), submetendo-se a mistura a uma agitação semivigorosa (aproximadamente $200 \mathrm{rpm}$ ) por cerca de 1 minuto no frasco hermeticamente fechado. Este procedimento fez com que houvesse a homogeneização do composto adicionado, bem como auxiliou na dispersão da celulose microcristalina (já que esta última decantou durante o resfriamento). Depois que a mistura foi homogeneizada, esta foi colocada em placas de alumínio com $10 \mathrm{~mm}$ de profundidade e $0,11 \mathrm{~m}$ de diâmetro, sendo rapidamente coberta com uma tampa de vidro circular de 0,12 m de diâmetro, tomando-se o cuidado para que não houvesse a formação de bolhas na superfície da amostra. A mistura geleificou nas placas de alumínio, ficando em repouso à temperatura ambiente por 15 horas; obteve-se, dessa forma, o sistema-modelo.

Após os testes com diferentes formulações da matriz sólida do sistema-modelo composta por ágar como agente geleificante, chegou-se à composição final apresentada na Tabela 2.

Conforme pode ser observado, os teores de água, celulose e açúcares do sistema-modelo se aproximaram aos do abacaxi (Tabela 1). Em todas as concentrações de ágar testadas $(1,0$ a 3,0\% p/p de ágar), as amostras apresentaram-se com uma estrutura sólida firme. Além disso, durante experimentos prévios de secagem, o sistema-modelo (com 1,7\% p/p de ágar) encolheu de maneira uniforme, com ausência de fissuras ou rachaduras, apresentando um comportamento semelhante ao do abacaxi durante a secagem. Segundo a metodologia empregada na elaboração do sistema-modelo (14,8 g de solução aquosa contendo $1000 \mathrm{mg}$ aroma. $\mathrm{kg}^{-1}$ solução adicionados em $100 \mathrm{~g}$ de insumos misturados inicialmente), a concentração teórica de aroma foi de $129 \mathrm{mg} . \mathrm{kg}^{-1}$ sistema-modelo.

\subsection{Extração e determinação do componente do aroma do sistema-modelo}

O sistema-modelo (na forma de gel) foi cortado em pequenos pedaços e colocado em um recipiente hermeticamente fechado juntamente com $20 \%$ p/p de água destilada, a fim de ser fundido. A mistura foi submetida à agitação com aquecimento (realizado pelos agitadores magnéticos utilizados no desenvolvimento do sistema-modelo) por um tempo de aproximadamente 14 minutos, quando então a temperatura atingiu cerca de $78-80{ }^{\circ} \mathrm{C}$ e a amostra fundiu. $\mathrm{O}$ volume máximo ocupado pela fase vapor no interior do frasco foi de aproximadamente $20 \%$ do volume total, a fim de se minimizarem as perdas de aroma. Depois que a amostra fundiu, foi resfriada à temperatura ambiente por aproximadamente 15 minutos até que a sua temperatura atingisse de $58{ }^{\circ} \mathrm{C}$ a $60{ }^{\circ} \mathrm{C}$, sendo rapidamente agitada para a homogeneização da mistura. Por fim, uma alíquota de amostra foi submetida à extração do aroma.

Para a extração do aroma, uma alíquota ao redor de $4 \mathrm{~g}$ de amostra de sistema-modelo na forma líquida (temperatura de aproximadamente $55^{\circ} \mathrm{C}$ ), foi rapidamente adicionada a $16 \mathrm{~mL}$ de

Tabela 2. Composição média do sistema-modelo substitutivo do abacaxi a ser utilizado durante a secagem em atmosferas normal e modificada.

\begin{tabular}{lcc}
\hline \multicolumn{1}{c}{ Componentes } & $\begin{array}{c}\text { Composição média } \\
\left(\mathrm{g} .100 \mathrm{~g}^{-1} \text { amostra }\right)^{*}\end{array}$ & $\begin{array}{c}\text { Incerteza } \\
\left(\mathrm{g} .100 \mathrm{~g}^{-1} \text { amostra }\right)^{*}\end{array}$ \\
\hline Água & 85,1 & 0,1 \\
Celulose & 0,4 & $<0,1$ \\
Sacarose & 8,4 & $<0,1$ \\
Glicose & 2,2 & $<0,1$ \\
Frutose & 2,2 & $<0,1$ \\
Ágar & 1,7 & $<0,1$ \\
Hexanoato de etila mg.kg ${ }^{-1}$ & 129 & 1,0 \\
\hline
\end{tabular}

${ }^{\star}$ Composição percentual exceto para o composto de aroma. 
hexano (relação Volume de amostra/Volume de hexano = 1:4), previamente aquecido a $50^{\circ} \mathrm{C}$ em banho finito, em um pequeno frasco com volume total de $24 \mathrm{~mL}$ hermeticamente fechado. $\mathrm{O}$ pré-aquecimento do hexano é essencial, a fim de que a amostra não solidifique instantaneamente ao entrar em contato com este solvente. A amostra foi submetida à agitação semivigorosa (200 rpm) por 4 horas no banho finito e mantida na temperatura de $50{ }^{\circ} \mathrm{C}$ com aquecimento constante, a fim de que o sistema permanecesse no estado líquido. Após o processo de extração do aroma no hexano, a amostra decantou (mais densa do que o solvente) e a mistura se apresentou com duas fases separadas. Então, retirou-se uma alíquota da fase hexano, a qual foi injetada em um cromatógrafo gasoso. Segundo a metodologia de extração descrita, a concentração teórica inicial de aroma de 129 mg.kg-1 sistema-modelo equivale a uma quantidade extraída de aproximadamente $40 \mathrm{mg}$ aroma. $\mathrm{kg}^{-1}$ hexano.

O hexanoato de etila (utilizado como padrão de aroma do sistema-modelo) foi analisado cromatograficamente. Foi observado que o seu limite de deteç̧ão foi a uma concentração de $3 \mathrm{mg} \cdot \mathrm{kg}^{-1}$ solvente, equivalente a aproximadamente $10 \mathrm{mg} \cdot \mathrm{kg}^{-1}$ sistema-modelo; este valor é cerca de 13 vezes menor do que a concentração teórica inicial de aroma no sistema-modelo, o que é interessante para experimentos futuros de cinética de secagem.

Fez-se uma curva-padrão do padrão de aroma presente nas amostras do sistema-modelo, a fim de que a sua concentração pudesse ser determinada. Na Figura 5, apresenta-se a curva-padrão de hexanoato de etila em hexano.

Segundo as condições cromatográficas utilizadas para a detecção do sistema-modelo, o seu tempo de retenção aproximado foi de 14,7 minutos.

$\mathrm{O}$ sistema-modelo foi submetido à secagem em atmosferas normal e modificada com $0,5 \%$ (v/v) de etanol $96{ }^{\circ} \mathrm{GL}$ a $50^{\circ} \mathrm{C}\left( \pm 1{ }^{\circ} \mathrm{C}\right)$ e velocidade do gás de secagem de $0,84 \mathrm{~m} /$ segundo ( $\pm 0,05 \mathrm{~m} /$ segundo). A umidade relativa do gás de secagem tanto em atmosfera normal quanto em atmosfera modificada foi de $14 \pm 3 \%$. Na Figura 6, apresenta-se a curva de evaporação do hexanoato de etila nos períodos de secagem entre 60 e 360 minutos. A cinética de evaporação do aroma foi quantificada pela relação entre concentração de hexanoato de etila no sistema-modelo seco e no sistema-modelo antes da secagem. A referida concentração foi obtida com base na massa de sólido seco das amostras.

A evaporação do aroma foi menos intensa em atmosfera modificada com etanol do que em atmosfera normal. Pôde ser observada a formação de uma crosta na superfície do gel

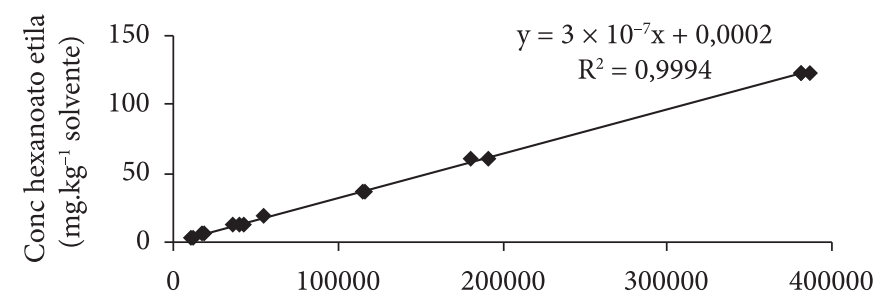

Área dos picos (counts)

Figura 5. Curva-padrão de hexanoato de etila em hexano. durante a secagem, principalmente em atmosfera modificada, sugerindo que tanto a presença do etanol quanto a presença da referida crosta influenciaram na maior retenção do aroma em atmosfera modificada.

\subsection{Extração e determinação dos voláteis do abacaxi}

\section{Tipo de solvente}

Na Figura 7, são apresentados os resultados obtidos nos cromatogramas referentes às áreas dos picos dos principais voláteis extraídos de amostras de abacaxi in natura, usando-se dois tipos de solvente para a eluição do aroma: hexano e éter etílico. O tempo de extração foi de 3 horas. Ressalta-se que o hexano foi escolhido por ser um solvente com características apolares e o éter etílico por ter uma polaridade maior.

Os cromatogramas dessas análises indicaram que os tempos de retenção dos voláteis na coluna cromatográfica eluídos por hexano e por éter etílico foram semelhantes. Tal fato levou a crer que os dois tipos de solvente extraíram os mesmos compostos, porém em intensidades diferentes. A eluição realizada com o éter etílico promoveu uma maior remoção dos compostos do aroma do abacaxi da armadilha, indicando que um solvente com características mais polares extrai com maior eficiência os referidos compostos do polímero Porapak Q. Foi realizada uma análise estatística com os resultados das áreas para os dois solventes, usando um intervalo de confiança de $95 \%$. As

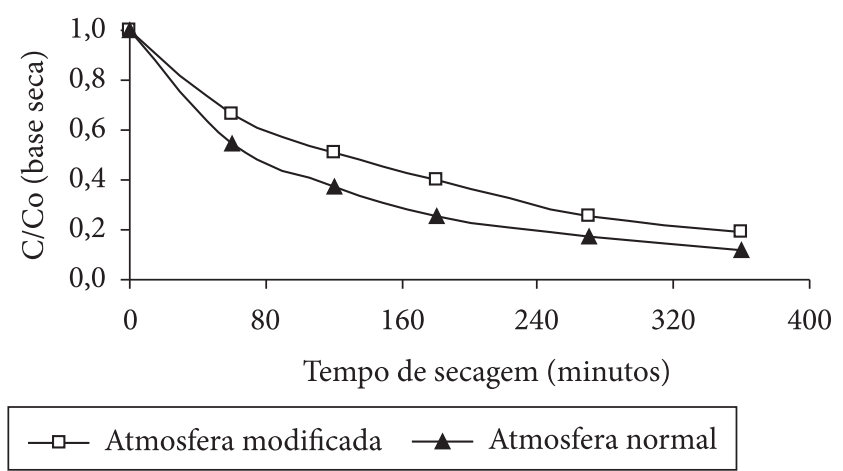

Figura 6. Retenção de aroma (hexanoato de etila) nas amostras de sistema-modelo durante a secagem $\left(50{ }^{\circ} \mathrm{C}\right.$ e $0,84 \mathrm{~m} /$ segundo), em atmosferas normal e modificada com $0,5 \%(\mathrm{v} / \mathrm{v})$ de etanol.

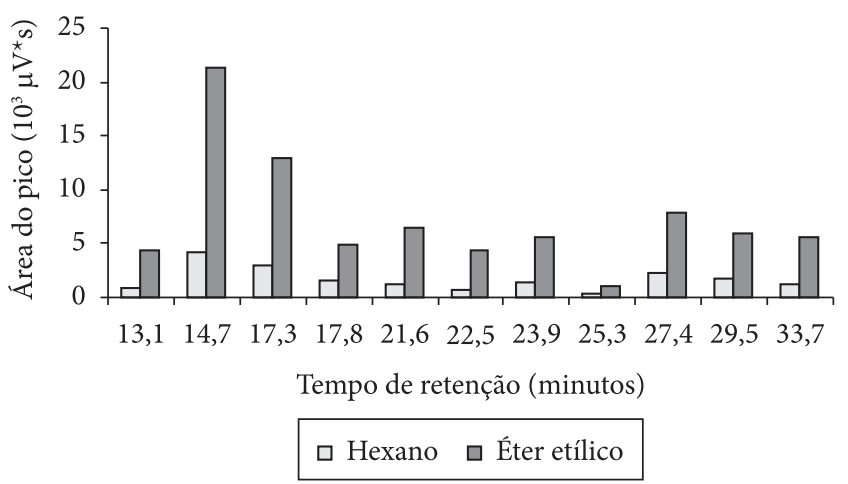

Figura 7. Área dos picos dos principais voláteis extraídos (3 horas de extração) do abacaxi in natura eluídos por dois tipos de solvente. 
diferenças nas áreas dos picos para os dois solventes foram significativas $(p=0,002)$. Assim, o éter etílico foi definido como o solvente a ser utilizado para a eluição dos compostos presentes no abacaxi in natura e seco.

\section{Tempo de extração do aroma do abacaxi}

Os tempos de extração utilizados nos testes do presente trabalho foram escolhidos a partir do estudo realizado por Thomazini (1998) sobre o tempo de coleta de compostos voláteis de frutas. Na Figura 8, pode-se verificar a influência do tempo de extração dos compostos do aroma do abacaxi in natura. $\mathrm{O}$ solvente utilizado na eluição foi o éter etílico.

Conforme pode ser observado na Figura 8, com 3 horas de extração, obteve-se uma maior intensidade de aroma extraído do headspace das amostras. Com 4,5 horas de extração, a taxa de dessorção dos compostos (provocada pela sucção para a formação do vácuo) é maior do que a taxa de adsorção do aroma no polímero poroso que constitui a armadilha. Por isso, o tempo de 3 horas foi o escolhido para a extração do aroma do headspace das amostras de abacaxi in natura ou seco.

Vale ressaltar que os resultados apresentados na Figura 7 para o éter etílico e os apresentados na Figura 8 com 3 horas de extração foram obtidos a partir das mesmas condições cromatográficas. Porém, a fruta utilizada não foi a mesma; por isso, as áreas dos picos dos componentes do aroma foram diferentes. No entanto, pode-se observar que os principais compostos extraídos foram praticamente os mesmos, pois o perfil cromatográfico das amostras foi semelhante.

\section{Avaliação dos voláteis do abacaxi in natura e seco}

A partir dos parâmetros analíticos de extração e determinação dos voláteis do aroma do abacaxi obtidos no presente trabalho (3 horas de extração e eluição por éter etílico), foram extraídos os compostos voláteis do abacaxi in natura ( $85 \%$ de umidade - base úmida) e seco (sob atmosfera normal, no sistema de secagem desenvolvido no presente trabalho (Figura 2) até dois teores de umidade final $(74 \%$ e $46 \%$ - base úmida, equivalentes 4 e 11 horas de secagem, respectivamente). O teor mais baixo de umidade foi escolhido de modo que os voláteis pudessem ser detectados; já o teor de $74 \%$ (base úmida) foi escolhido por ser um valor intermediário. A temperatura do gás de secagem foi de $60^{\circ} \mathrm{C}\left( \pm 1^{\circ} \mathrm{C}\right)$, a velocidade do mesmo foi de $0,84 \mathrm{~m} /$ segundo ( $\pm 0,05 \mathrm{~m} /$ segundo) e a umidade relativa foi de $10 \%( \pm 2 \%)$. Na Figura 9, estão apresentadas as áreas dos picos dos voláteis mais significativos para abacaxi in natura e seco, por massa de sólido seco. Observou-se que, para as amostras secas, até mesmo em níveis de umidade relativamente baixos ( $46 \%$ base úmida), os voláteis extraídos foram praticamente os mesmos, variando apenas a intensidade. Somente o composto cujo tempo de retenção foi em torno de 30,4 minutos não foi detectado nas amostras secas.

Amostras-padrão de hexanoato de etila (padrão de aroma utilizado no sistema-modelo) em éter etílico, em concentrações de 1,10 e $100 \mathrm{mg} \cdot \mathrm{kg}^{-1}$ solvente foram injetadas no cromatógrafo gasoso, utilizando-se as mesmas condições cromatográficas da análise do aroma de abacaxi. Esse procedimento foi realizado

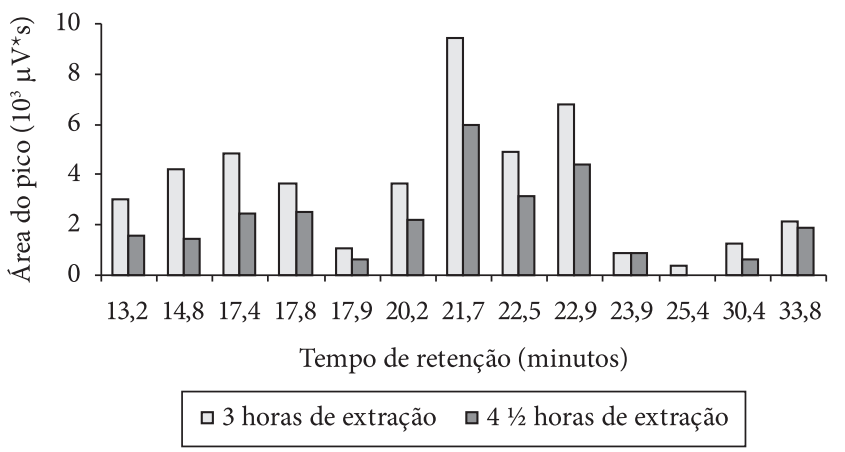

Figura 8. Área dos picos dos principais voláteis extraídos do headspace de amostras de abacaxi in natura, utilizando-se diferentes tempos de extração.

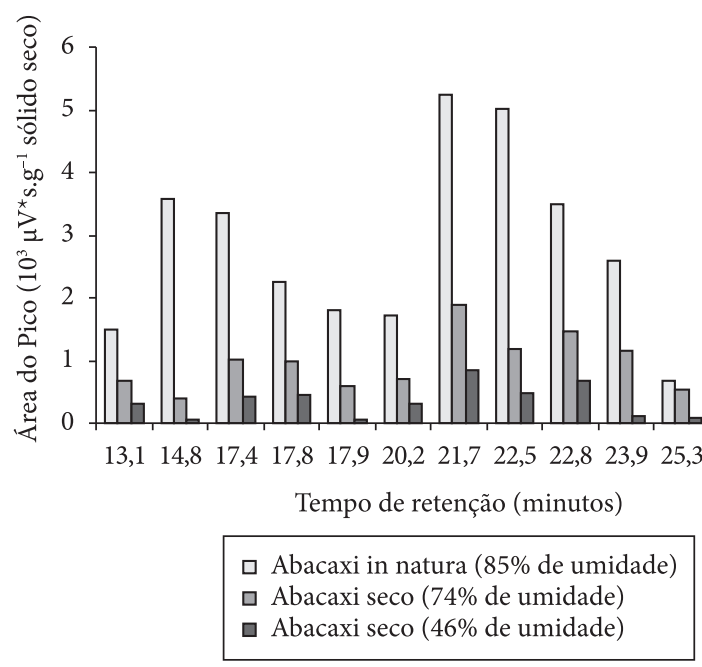

Figura 9. Área dos picos dos compostos voláteis extraídos (3 horas de extração) do abacaxi in natura e seco eluídos por éter etílico.

a fim de que fosse possível identificar o hexanoato de etila nos cromatogramas de abacaxi, em diferentes concentrações, a partir do seu tempo de retenção na coluna cromatográfica. Pôde-se observar que o pico do hexanoato apareceu no tempo de retenção ao redor de 17,3 minutos nas diversas concentrações testadas. Comparando-se este tempo de retenção com os das amostras analisadas neste trabalho (Figuras 7 a 9), verificou-se que o hexanoato apareceu em todas as amostras, mostrando que é um dos compostos mais importantes do aroma de abacaxi. Ressalta-se que os tempos de retenção do hexanoato de etila presente no sistema-modelo (14,7 minutos) e no aroma do abacaxi (17,3 minutos) foram diferentes, pois as condições cromatográficas não puderam ser as mesmas.

\section{Conclusões}

O trabalho realizado é um subsídio inicial ao estudo da secagem em atmosfera modificada. Além do sistema de secagem mostrado, consideram-se como contribuições deste trabalho:

- O desenvolvimento de um sistema-modelo sólido a partir da composição centesimal química do abacaxi com uma composição final definida; 
- O desenvolvimento de uma metodologia de extração do hexanoato de etila presente no sistema-modelo, por meio da extração em hexano, cuja concentração foi determinada por cromatografia gasosa; e

- O desenvolvimento de uma metodologia de extração do aroma do abacaxi in natura e seco, a partir da captura dos voláteis presentes, sendo que estes foram determinados por cromatografia gasosa.

\section{Agradecimentos}

Os autores agradecem à FAPESP (Fundação de Amparo à Pesquisa do Estado de São Paulo) pela Bolsa de Doutorado concedida.

\section{Referências bibliográficas}

BELITZ, H-D.; GROSCH, W. Química de los alimentos. Zaragoza: Editorial Acríbia S. A., 1988.

FRANCO, M. R. B.; RODRIGUEZ-AMAYA, D. B. Trapping of soursop (Annona muricata) juice volatile on Porapak Q by suction. Journal of Science of Food and Agriculture, v. 34, n. 3, p. 293-299, 1983. http://dx.doi.org/10.1002/jsfa.2740340313

GARRUTI, D. S. Composição de voláteis e qualidade de aroma do vinho de caju. 2001. 118 f. Tese (Doutorado em Ciência de Alimentos)-Faculdade de Engenharia de Alimentos, Universidade Estadual de Campinas, Campinas, 2001.

HAWLADER, M. N. A.; PERERA, C. O.; TIAN, M. Comparison of the retention of 6-Gingerol in drying of ginger under modified atmosphere heat pump drying and other drying methods. Drying Technology, v. 24, n. 1, p. 51-56, 2006. http://dx.doi. org/10.1080/07373930500538675

HAWLADER, M. N. A. et al. Drying of guava and papaya: impact of different drying methods. Drying Technology, v. 24, n. 1, p. 77-87, 2006. http://dx.doi.org/10.1080/07373930500538725

KAIRUI, Z.; PAKOWSKI, Z. Drying properties of ejiao. In: INTERNATIONAL DRYING SYMPOSIUM (IDS '96), 10., 1996, Kraków, Poland. Proceedings... Kraków, 1996. v. B, p. 1255-1260.

KUDRA, T.; POIRIER, M. Drying in gaseous $\mathrm{CO}_{2}$. In: INTERAMERICAN DRYING CONFERENCE (IADC), 3., 2005, Montreal, Canada. Proceedings... Montreal, 2005. Paper n. XII-3. 1 CD-ROM.

LIU, X. et al. Estimating retention of emulsified flavor in a single droplet during drying. In: INTERNATIONAL DRYING SYMPOSIUM (IDS' 2000), 12., 2000, Noordwijkerhout, Netherlands. Proceedings... Noordwijkerhout: Elsevier Science B.V., 2000. Trabalho n. 226. CD-ROM.
LUNA, F.; MARTÍNEZ, J. Stability of the dynamical system describing gas-phase-controlled drying of ternary mixtures. In: INTER-AMERICAN DRYING CONFERENCE (IADC), 1997, Itu, Brazil. Proceedings... Campinas: UNICAMP, 1997.v. A, p. 99-106.

MAARSE, H. Introduction. In: MAARSE, H. (Ed.). Volatile compounds in foods and beverages. New York: Marcel Dekker, Inc., 1991. p. 1-39.

MEDINA, J. C. et al. Abacaxi: cultura, matéria-prima, processamento e aspectos econômicos. 2. ed. Campinas: ITAL, 1987.

MORAIS, M. M.; SILVA, M. A. Preliminary study of pineapple aroma retention in drying with preloaded gas. In: INTERNATIONAL DRYING SYMPOSIUM (IDS’ 2004), 14., 2004, São Paulo. Proceedings... Campinas: Unicamp, 2004. v. C, p. 1620-1627.

MORAIS, M. M.; SANTOS, P. H. S.; SILVA, M. A. Estudo da retenção de voláteis na secagem em atmosfera modificada: desenvolvimento de um sistema modelo. In: CONGRESSO BRASILEIRO DE SISTEMAS PARTICULADOS (ENEMP 2004), 31., 2004, Uberlândia. Anais.. Uberlândia, 2004. v. 1, p.69-69. CD-ROM.

O'NEILL, M. B. et al. Color and density of apple cubes dried in air and modified atmosphere. International Journal of Food Properties, v. 1, p. 197-205, 1998. http://dx.doi.org/10.1080/10942919809524577

PANG, S. Using methanol and ethanol vapours as drying media for producing bright color wood in drying of Radiata pine. In: INTERNATIONAL DRYING SYMPOSIUM (IDS’ 2006), 15., 2006 , Budapest, Hungary. Proceedings... Budapest, 2006. p. 1745-1749.

RAMESH, M. N. et al. Studies on inert gas processing of vegetables. Journal of Food Engineering, v. 40, p. 199-205, 1999. http://dx.doi org/10.1016/S0260-8774(99)00056-4

SCHULTZ, P.; SCHLÜNDER, E. U. Influence of additivies on crust formation during drying. Chemical Engineering and Processing, v. 28, p. 133-142, 1990. http://dx.doi.org/10.1016/02552701(90)80010-3

TAKEOKA, G. et. al. Volatile constituents of pineapple (Ananas Comosus [L.] Merr.). In: TERANISHI, R.; BUTTERY, R. G.; SHAHIDI, F. Flavor chemistry: trends and developments. Washington: ACS, 1989. p. 223-237.

THOMAZINI, M. Composição de voláteis de sucos provenientes da fruta e polpa congeladas de umbu (Spondias tuberosa, Anacardiaceae). 1998. 91 f. Dissertação (Mestrado em Ciência de Alimentos)-Faculdade de Engenharia de Alimentos, Universidade Estadual de Campinas, Campinas, 1998.

TIETZ, M.; SCHLÜNDER E. U. Through drying of paper. Part II: Additives in the air improve product quality. Chemical Engineering and Processing, v. 32, p. 161-165, 1993. http://dx.doi. org/10.1016/0255-2701(93)80012-6 